\section{Management of Pest Insects and Plant Diseases in Fruit and Nursery Production with Laser-guided Variable-rate Sprayers}

\author{
Liming Chen, Heping Zhu, and Leona Horst \\ Application Technology Research Unit, Agricultural Research Service, U.S. \\ Department of Agriculture, 1680 Madison Avenue, Wooster, OH 44691
}

Matthew Wallhead

University of Maine Cooperative Extension, 495 College Avenue, Orono, ME 04473

\author{
Michael Reding \\ Application Technology Research Unit, Agricultural Research Service, U.S. \\ Department of Agriculture, 1680 Madison Avenue, Wooster, OH 44691
}

Amy Fulcher

University of Tennessee, 2505 E.J. Chapman Drive, Knoxville, TN 37996

Additional index words. environmental protection, pest control, precision sprayer, orchard, sustainable agriculture

\begin{abstract}
Laser-guided variable-rate intelligent spray technology is anticipated to reduce pesticide use in production of crops and safeguard the environment. However, the ability of this technology to effectively control insect pests and diseases of crops must be validated before it becomes part of integrated pest management programs. Abilities of three different intelligent sprayers were tested to control pest insects and plant diseases at one fruit farm and two ornamental nurseries in Ohio during three consecutive growing seasons. The same sprayers with disabled intelligent functions were used as conventional constant-rate applications for comparisons. Test crops were apple (Malus pumila), peach (Prunus persica), blueberry (Vaccinium sect. Cyanococcus), black raspberry (Rubus occidentalis), crabapple (Malus sp.), maple (Acer sp.), birch (Betula sp.), and dogwood (Cornus florida). There were five insects and six diseases total involved in the investigations in the fruit farm and two nurseries. The field tests showed the intelligent spray applications reduced pesticide and foliar fertilizer use by $\approx 30 \%$ to $65 \%$ on average during the 3-year experiments. At the same time, intelligent spray technology was similar or more effective than conventional spray technology when controlling insects and diseases on a variety of crops. These results demonstrated that intelligent spray technology was environmentally friendly and more effective for control of insect and disease pests in fruit farms and ornamental tree nurseries.
\end{abstract}

Received for publication 2 Oct. 2020. Accepted for publication 6 Nov. 2020.

Published online 8 December 2020.

This research was supported by the U.S. Department of Agriculture, National Institute of Food and Agriculture, Specialty Crop Research Initiative Project 2015-51181-24253 and Horticulture Research Institute Project 1379-649. We acknowledge Moreland Fruit Farm, Willoway Nurseries Inc., and Herman Losely \& Son, Inc. for their generosity in providing facilities, labor, and resources for the experiments.

Mention of proprietary product or company is for the reader's convenience and does not imply any endorsement or preferential treatment by Agricultural Research Service, U.S. Department of Agriculture.

H.Z. is the corresponding author. E-mail: heping. zhu@usda.gov.

This is an open access article distributed under the CC BY-NC-ND license (https://creativecommons. org/licenses/by-nc-nd/4.0/). active ingredients were applied on nursery and floriculture crops in California, Florida, Michigan, Oregon, Pennsylvania, and Texas (U.S. Department of Agriculture/National Agricultural Statistics Service, 2011).

In the United States, codling moth (Cydia pomonella) is the most serious pest in apple fruit (Beckerman, 2018), and oriental fruit moth (Grapholita molesta) is one of the most damaging pests in peach fruit (Brunner and Rice, 1993). Spotted wing drosophila (Drosophila suzukii) has been a serious pest of blueberry and black raspberry over the past 10 years (Fulcher et al., 2015). Potato leafhopper (Empoasca fabae) is a severe pest of maple trees in the Eastern United States (Frank et al., 2013). Aphids, including several genera, are one of the insects feeding on birch in Ohio (Division of Forestry, Ohio Department of Natural Resources, 2018). Insecticide treatments are the primary method for controlling these insect pests.

Apple scab (Venturia inaequalis) is a serious disease of apple and crabapple worldwide, leading to the greatest loss in apple yield among the apple diseases (Ellis, 2008). Powdery mildews are common foliar diseases on apple, peach, and dogwood trees (Blake et al., 2016; Ellis, 2016a; Witte et al., 2000). Brown rot (Monilinia fructicola) is the most serious disease for peach under warm and humid conditions (Hartman, 2007). Mummy berry (Monilinia vaccinia-corymbosi) is one of the most serious fruit diseases, and phomopsis (Phomopsis vaccinii) is the most common canker disease for blueberry (Anco and Ellis, 2011; Fulcher et al., 2015). Anthracnose (Elsinoe veneta) is an extremely serious disease of black raspberry in the United States (Ellis, 2016b). Treatments of fungicides are the primary tactics for controlling these diseases.

For applying pesticides on fruit farms and ornamental nurseries, the most used spray equipment are radial air-assisted sprayers (Zhu et al., 2017). These sprayers deliver pesticides at a constant rate, and they are usually configured and operated to apply pesticides to the entire field regardless of the absence of plants in rows, plant structure conditions, and plant growth stage, resulting in plants being under- or over-sprayed (Zhu et al., 2008). At the same time, a significant portion of the spray drifts to nontarget areas (Zhu et al., 2006b), which wastes pesticides, contaminates the environment, and exposes applicators, workers, and other people to pesticides, while increasing the costs of production. Many spray methods have been evaluated for improving application efficiency of pesticides in fruit farms and ornamental nurseries (Jeon and Zhu, 2012; Stover et al., 2003; Zhu et al., 2006a, 2006b, 2011b).

A laser-guided variable-rate intelligent sprayer was developed to increase the application efficiency of pesticides and foliar products in fruit farms and ornamental nurseries (Chen et al., 2012; Shen et al., 2017). The intelligent sprayer system uses a sensor to control pesticide application rate by adjusting the spray output of each nozzle based on 
the presence, structure, and foliage density of the crop, and the travel speed in real time. Chen et al. (2013a) reported that the intelligent spray system reduced spray volume from $47 \%$ to $73 \%$ at three different phenological stages of apple, compared with a conventional sprayer. Fessler et al. (2020) also reported that spray volume could be reduced between $59 \%$ and $83 \%$ after an airassisted trailer sprayer was retrofitted with the laser-guided variable-rate control system in a commercial 8-year old Malus domestica 'Golden Delicious' apple orchard. No difference was found in spray coverage on sterling silver linden (Tilia tomentosa) and northern red oak (Quercus rubra) trees in ornamental nurseries between intelligent and conventional spray systems (Zhu et al., 2017), while the intelligent system reduced spray volume and drift to nontarget sites (Chen et al., 2013b).

Manandhar et al. (2020) reported that using an intelligent sprayer in Ohio apple orchards could reduce pesticide costs by $60 \%$ to $67 \%$, with cost savings between $\$ 1420$ and $\$ 1750$ per ha. Within 1 to 4 years of using the intelligent sprayer in these apple orchards, the cost savings for a 4- to 20-ha apple orchard was estimated to equal the investment of the sprayer. However, to make the technology more versatile, its efficacy must be validated in complying with complex canopies of nursery and orchard crops under different environmental conditions, and it must be included in the integrated pest management (IPM) programs in the future.

The hypothesis of this research was that use of the laser-guided variable-rate intelligent sprayer under commercial fruit and ornamental nursery tree production conditions would significantly reduce pesticide volume needed to control insect pests and diseases. Thus, the objective was to evaluate efficacy of intelligent and conventional spray technologies for controlling insect and disease pests in a commercial fruit farm and two ornamental nurseries, while comparing pesticide use by the different spray technologies.

\section{Materials and Methods}

Test sites. Field studies were conducted at a commercial fruit farm (Moreland Fruit Farm, lat. 40.711711, long. -81.969128) located in Wayne County, OH, and two commercial nurseries, located in Lorain County, OH (Willoway Nurseries, Inc., lat. 41.427065, long. -82.049974), and Lake County, OH (Herman Losely \& Son Nursery, Inc., lat. 41.755844, long. -81.161971). These nurseries are located on the south side of Lake Erie, about $100 \mathrm{~km}$ apart. Hereafter, they are referred to as Fruit Farm, Nursery-1, and Nursery-2, respectively. Apple, peach, blueberry, and black raspberry were selected as test crops at Fruit Farm. Crabapple, maple, and birch were used at Nursery-1; and apple, maple, birch, and dogwood were used at Nursery-2 for the test. The field plots for each crop were divided into two equal sections: one section for the intelligent spray treatment and the other for the conventional.
At Fruit Farm, all crops were field production sites. Codling moth mating disruption dispensers were placed in the apple trees at a rate of 300 dispensers per acre, and oriental fruit moth mating disruption dispensers were placed in the peach trees at a rate of 150 dispensers per acre in 2017 and 2018 , in combination with pesticide applications for each pest. During the growing season of 2019, insecticides alone were used to control codling moth and oriental fruit moth (mating disruption dispensers were not used for either pest). For each fruit crop, the same plants and same plots were used for the entire 3-year experiment from 2017 to 2019. Effective nutrient management of fruit plants may improve fruit yield and quality and induce insect pest and disease tolerance. Currently, fruit growers achieve optimum nutrition through soil applications, in combination with foliar sprays. Because foliar fertilization applies in controlled quantities and is more environmentally friendly, it is considered a key factor to optimum nutrient management of fruit trees. Therefore, at Fruit Farm, foliar fertilization sprays were also included in the experiment for all fruit crops. Experimental plants, spray times, and pests of study for the Fruit Farm are shown in Table 1.

At Nursery-1, all plants were grown in a "pot in pot" multiple-row production system. Test plants and plots were changed every year. At Nursery-2, all plants were grown directly in the field. The same apple, maple, and dogwood trees and plots were used to conduct the tests for the entire experiment of three consecutive growing seasons from 2017 to 2019 . For birch, the same plants and plots were used for the growing seasons of 2017 and 2018, and the plants and plots were changed in 2019. Experimental plants, spray times, and pests of study for the nurseries are shown in Table 1.

Intelligent sprayers for tests. Three conventional air-assisted sprayers modified to become the laser-guided variable-rate intelligent sprayers used for this study are shown in Fig. 1. The sprayer at the top-right in the figure was used in Fruit Farm. It was a multiport airassisted vineyard sprayer mainly consisting of an axial fan, a 400-L spray tank, a diaphragm pump, and four specially designed five-port nozzle manifolds mounted on each side of the sprayer. There were five nozzle tips in each manifold to discharge fan-pattern sprays. Heights of the four manifolds were 0.85 , $1.35,1.85$, and $2.35 \mathrm{~m}$ above the ground.

The sprayer at middle-right in Fig. 1 was used in Nursery-1. It was a custom-made airassisted tower sprayer consisting of a $3785-\mathrm{L}$ spray tank, an axial fan, and two vertical ducts on each side. The airflow exited from the two ducts horizontally. The sprayer was fitted with 18 hollow-cone nozzles placed at $20 \mathrm{~cm}$ apart vertically along each duct. Spray clouds were carried, introduced by the

Table 1. Test site, plant type, pesticide application year, number of spray applications, and pests of study for conventional and intelligent spray treatments at Fruit Farm, Nursery-1, and Nursery-2 from 2017 to 2019.

\begin{tabular}{|c|c|c|c|c|}
\hline \multirow[b]{2}{*}{ Test site } & \multirow[b]{2}{*}{ Plant } & \multicolumn{2}{|c|}{ Pesticide application } & \multirow[b]{2}{*}{ Pests of study } \\
\hline & & Yr & Times & \\
\hline \multirow[t]{12}{*}{ Fruit Farm } & Apple & 2017 & 15 & Codling moth, scab, powdery mildew \\
\hline & & 2018 & 14 & \\
\hline & & 2019 & 13 & \\
\hline & Peach & 2017 & 9 & Oriental fruit moth, brown rot, \\
\hline & & 2018 & 11 & powdery mildew \\
\hline & & 2019 & 10 & \\
\hline & Blueberry & 2017 & 11 & Spotted wing drosophila, mummy \\
\hline & & 2018 & 7 & berry, phomopsis \\
\hline & & 2019 & 7 & \\
\hline & Black raspberry & 2017 & 7 & Spotted wing drosophila, anthracnose \\
\hline & & 2018 & 4 & \\
\hline & & 2019 & 3 & \\
\hline \multirow[t]{9}{*}{ Nursery-1 } & Crabapple & 2017 & 15 & Scab \\
\hline & & 2018 & 12 & \\
\hline & & 2019 & 16 & \\
\hline & Maple & 2017 & 15 & Leafhopper \\
\hline & & 2018 & 14 & \\
\hline & & 2019 & 14 & \\
\hline & Birch & 2017 & 15 & Aphid \\
\hline & & 2018 & 8 & \\
\hline & & 2019 & 15 & \\
\hline \multirow{12}{*}{ Nursery-2 } & Apple & 2017 & 4 & Scab \\
\hline & & 2018 & 3 & \\
\hline & & 2019 & 4 & \\
\hline & Maple & 2017 & 2 & Leafhopper \\
\hline & & 2018 & 2 & \\
\hline & & 2019 & 2 & \\
\hline & Birch & 2017 & 2 & Aphid \\
\hline & & 2018 & 2 & \\
\hline & & 2019 & 2 & \\
\hline & Dogwood & 2017 & 2 & Powdery mildew \\
\hline & & 2018 & 2 & \\
\hline & & 2019 & 2 & \\
\hline
\end{tabular}




\section{Universal automatic control system to retrofit on existing sprayers}

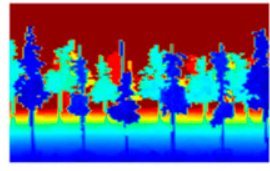

Algorithms

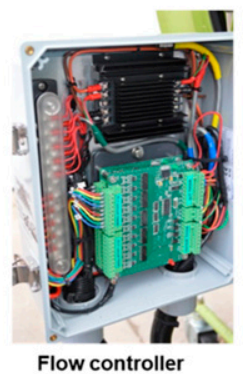

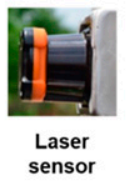

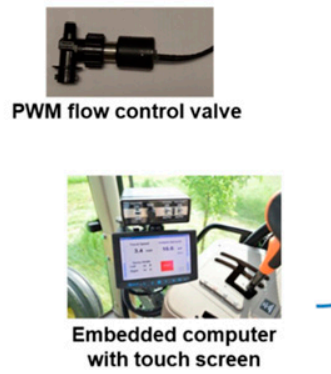

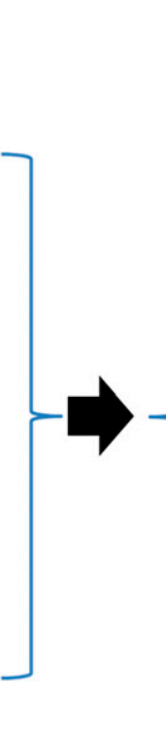

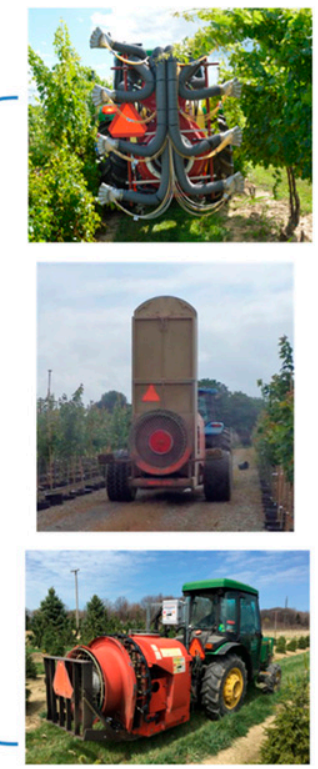

Fig. 1. Three air-blast sprayers retrofitted with the intelligent spray system used for tests at Fruit Farm (top), Nursery-1 (middle), and Nursery-2 (bottom).

airflow, horizontally toward the tree canopy. The operating pressure was $690 \mathrm{kPa}$, and the travel speed was $4.8 \mathrm{~km} \cdot \mathrm{h}^{-1}$.

The sprayer at the bottom-right in Fig. 1 was used in Nursery-2. It was a radial airblast sprayer consisting of a $450-\mathrm{L}$ spray tank, an axial-flow fan, and seven hollowcone nozzles on each side. The airflow exited in a radial pattern and carried the spray cloud into the canopy. Spray droplets were discharged from nozzles mounted on the radius of a 1.0-m diameter fan outlet and carried by the high-speed airflow into crops. The top and the bottom nozzles at each side were shut off for the test. The sprayer was operated at 830 $\mathrm{kPa}$ and traveled at $6.4 \mathrm{~km} \cdot \mathrm{h}^{-1}$.

These three conventional sprayers were retrofitted with the same spray control system (Fig. 1), which included a laser scanning sensor, a speed sensor, an automatic nozzle flow rate controller, an embedded computer with algorithms, a touch screen, an automaticmanual switch box, and variable-rate nozzles, each coupled with a pulse width modulated flow control valve on an air-assisted delivery system (Shen et al., 2017). The sprayers could be manually switched to discharging spray solutions at constant rates by toggling the switch box, which was used as a conventional spray for this study. Detailed information about these intelligent sprayers has been reported previously (Shen et al., 2017). During intelligent spray applications, the automatic control function was active through the switch box. Tree canopy presence, size, shape, leaf density, and sprayer ground speed were sensed and used to calculate and apply the appropriate amount of pesticide and foliar products in real-time. During the application, variable-rate outputs of each nozzle were controlled automatically from zero to its maximum flow rate to match the tree canopy presence and structures as well as the sprayer ground speed. For conventional spray appli- cations (variable-rate function disabled), all sprayer nozzles were activated to discharge the flow rates set at the pressure designated for their specific sprayer. The designated pressures were 345,620 , and $690 \mathrm{kPa}$ for the sprayers used in Fruit Farm, Nursery-1, and Nursery-2, respectively. Intelligent and conventional sprayers traveled on both sides of each row at $5.6 \mathrm{~km} \cdot \mathrm{h}^{-1}$. Pesticide spray application times for the three growing seasons at the fruit farm and two ornamental nurseries are shown in Table 1. Pesticide and foliar fertilizer usages during each growing season were also recorded for both intelligent and conventional spray applications.

Assessments of insect pests and diseases. Populations of insect pests and severities of diseases were assessed at 1- to 3-week intervals. At Fruit Farm, the populations of codling moth in apple plots and oriental fruit moths in peach plots were monitored by Delta Pherocon VI traps with CM-DA COMBO lures (Trécé Inc., Adair, OK) and wing-style Pherocon traps with OFM lures (Trécé Inc.), respectively. Spotted wing drosophila were monitored by Pherocon SWD traps with broad spectrum lures (Trécé Inc.) in blueberry in 2017 and 2019 and in black raspberry in 2019 only. There were three traps representing three replications placed inside the canopies of each crop in the middle row of each treatment plot. Spacing between traps was $45 \mathrm{~m}$ in the apple and peach plots, and $30 \mathrm{~m}$ in the blueberry and black raspberry plots. The number of spotted wing drosophila larvae in blueberry fruits was determined by saturated salt flotation (Jasinski, 2017). Yellow sticky traps ( 3 in $\times 5$ in, BASF Corp., St. Louis, MO) were used to monitor populations of leafhopper in maples, and these were placed inside tree canopies with three replications at Nursery- 1 and six replications at Nursery-2. Populations of aphids in birch plots were assessed by randomly selecting five trees in each treatment, then randomly selecting 10 branches from each tree.

To assess the severity of brown rot infections in peach, three spots were randomly selected, 100 fruits in each spot were examined, and the proportion of infected fruits was recorded. To assess the severity of disease infections, 20 plants from each crop and treatment were randomly selected, and the proportion of infected trees, bushes, or fruits was observed and recorded on a basis of $0 \%$ (symptomless), $10 \%$ ( $10 \%$ of the plant had symptoms), and $100 \%$ (dead plant). The severity of each disease was then presented as a percentage from the proportion of infected trees, bushes, or fruits. The formula for calculating the area under the disease progress curve (AUDPC) was

$$
A_{k}=\sum_{i=1}^{N_{i}-1} \frac{\left(y_{i}+y_{i+1}\right)}{2}\left(t_{i}+1-t_{i}\right)
$$

where $t$ is the order of disease severity observation, $y_{i}$ is the disease level at $t=i$, $y_{0}$ is the initial infection or the disease level at $t=0$ (i.e., the first disease severity observation), and $A_{k}$ is the total accumulated disease level for AUDPC until $t=t_{k}$ (Madden et al., 2007).

Statistical analysis. It was a split plot design experiment that included two different spray applications as independent variables. Fields were not randomized yearly for each nursery. Because of the simple experimental design, results were analyzed using paired $t$ tests that included conventional and intelligent spray applications as independent variables, using Microsoft Excel 2016 (Redmond, WA). When the analysis generated a significant $F$ value $(P \leq 0.05)$ for treatments, different letters, $\mathrm{A}$ and $\mathrm{B}$, were marked after the means.

\section{Results and Discussion}

Pesticide and foliar fertilizer use. The average pesticide and foliar fertilizer use for conventional and intelligent spray applications in each experiment site is shown in Table 2. In 2017, the intelligent spray application reduced pesticide and fertilizer use by $52.8 \%$ at Fruit Farm, $65.2 \%$ at Nursery-1, and $56.4 \%$ at Nursery-2, compared with the conventional spray. Likewise in 2018 and 2019 at those three locations, the reductions were $47.1 \%$ and $38.8 \%$ at Fruit Farm, 54.7\% and $30.5 \%$ at Nursery- 1 , and $49.1 \%$ and $44.5 \%$ at Nursery-2, respectively. These results indicate that intelligent spray application reduces pesticide and foliar fertilizer use by $\approx 30 \%$ to $65 \%$ at the three experiment sites during the 3 -year experiments, which was comparable with a spray reduction of $53 \%$, compared with conventional spray in apple (Chen et al., 2013b).

At Fruit Farm and Nursery-2, the spray volume consumption gradually increased by intelligent spray technology from 2017 to 2019 (Table 2). This increase was because at 
Table 2. Comparisons of using pesticides and foliar fertilizers between conventional (Con) and intelligent (Int) spray applications at three different experimental sites (Fruit Farm, Nursery-1, and Nursery-2) from 2017 to 2019.

\begin{tabular}{|c|c|c|c|c|c|c|c|}
\hline \multirow[b]{2}{*}{$\mathrm{Yr}$} & \multirow[b]{2}{*}{ Application rate } & \multicolumn{2}{|c|}{ Fruit Farm } & \multicolumn{2}{|c|}{ Nursery-1 } & \multicolumn{2}{|c|}{ Nursery-2 } \\
\hline & & Con & Int & Con & Int & Con & Int \\
\hline & Change (\%) & & -52.8 & & -65.2 & & -56.4 \\
\hline 2018 & Average (L/ha) & $698 \mathrm{a}$ & $369 \mathrm{~b}$ & 508 a & $230 \mathrm{~b}$ & $470 \mathrm{a}$ & $239 \mathrm{~b}$ \\
\hline 2019 & Average (L/ha) & $657 \mathrm{a}$ & $402 \mathrm{~b}$ & $453 \mathrm{a}$ & $315 b$ & $470 \mathrm{a}$ & $261 \mathrm{~b}$ \\
\hline & Change (\%) & & -38.8 & & -30.5 & & -44.5 \\
\hline
\end{tabular}

${ }^{\mathrm{z}}$ Means followed by different letters in the same year and same site are significantly different $(P \leq 0.05$ level) using a paired $t$ test.
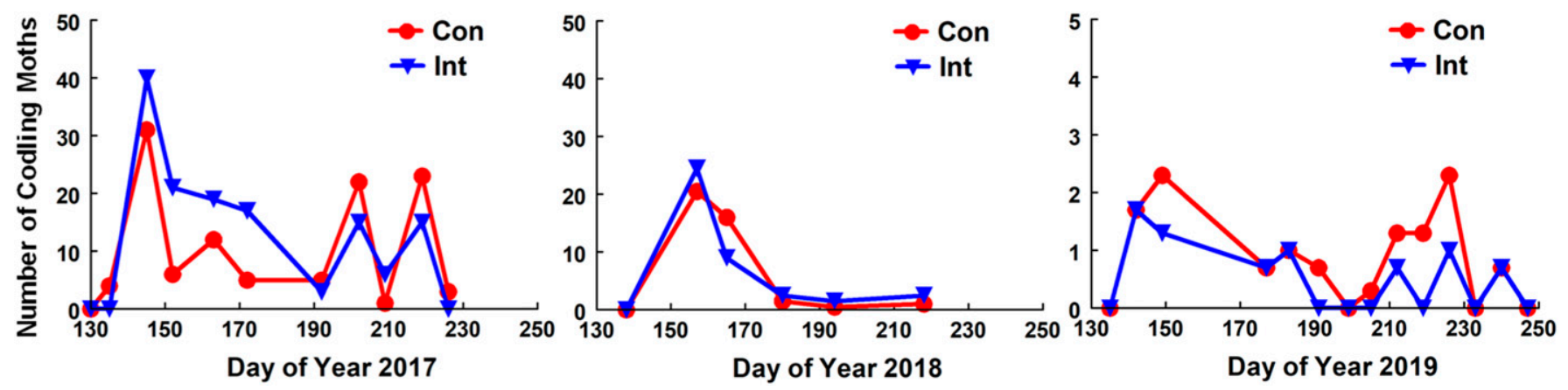

Fig. 2. Changes of average numbers of codling moths in traps in conventional constant-rate (Con) and intelligent variable-rate (Int) spray apple plots during three consecutive growing seasons from 2017 to 2019 at Fruit Farm. There was no statistical significance $(P \geq 0.05)$ by paired $t$ test between intelligent and conventional treatments on the same individual date.

Table 3. Comparisons of conventional (Con) and intelligent (Int) spray applications for the average numbers of spotted wing drosophila (SWD) in blueberry and black raspberry plots and SWD larvae in blueberry fruits at Fruit Farm. There was no statistical significance $(P \geq 0.05)$ by paired $t$ test between intelligent and conventional treatments on either blueberry or black raspberry in the same year.

\begin{tabular}{|c|c|c|c|c|c|c|}
\hline \multirow[b]{3}{*}{$\mathrm{Yr}$} & \multicolumn{4}{|c|}{ Blueberry } & \multirow{2}{*}{\multicolumn{2}{|c|}{$\frac{\text { Black raspberry }}{\mathrm{SWD} / \text { trap }}$}} \\
\hline & \multicolumn{2}{|c|}{ SWD/trap } & \multicolumn{2}{|c|}{ SWD larvae/150 fruits } & & \\
\hline & Con & Int & Con & Int & Con & Int \\
\hline 2017 & 43.7 & 33.0 & $\mathrm{~N} / \mathrm{A}$ & $\mathrm{N} / \mathrm{A}$ & $\mathrm{N} / \mathrm{A}$ & $\mathrm{N} / \mathrm{A}$ \\
\hline 2019 & 0.5 & 0.3 & 0.3 & 0 & 0.2 & 0.2 \\
\hline
\end{tabular}

$\mathrm{N} / \mathrm{A}=$ not applicable.

Table 4. Effects of conventional and intelligent spray treatments on the mean numbers of leafhoppers per trap in maple plots at Nursery-1 and Nursery-2.

\begin{tabular}{|c|c|c|c|c|}
\hline \multirow[b]{3}{*}{$\mathrm{Yr}$} & \multicolumn{4}{|c|}{ Mean number of leafhoppers } \\
\hline & \multicolumn{2}{|c|}{ Nursery-1 } & \multicolumn{2}{|c|}{ Nursery-2 } \\
\hline & Conventional & Intelligent & Conventional & Intelligent \\
\hline 2017 & $10.2 \mathrm{a}$ & $10.8 \mathrm{a}$ & $5.1 \mathrm{a}^{\mathrm{z}}$ & $3.3 \mathrm{~b}$ \\
\hline 2018 & $64.2 \mathrm{a}$ & $49.7 \mathrm{~b}$ & $8.9 \mathrm{a}$ & $7.7 \mathrm{~b}$ \\
\hline 2019 & $20.4 \mathrm{a}$ & $16.8 \mathrm{a}$ & $5.1 \mathrm{a}$ & $5.3 \mathrm{a}$ \\
\hline
\end{tabular}

${ }^{\mathrm{z}}$ Means followed by different letters in the same year and same nursery site are significantly different $(P \leq$ 0.05 level) using a paired $t$ test.

Table 5. Effects of conventional and intelligent spray treatments on the average numbers of aphids in a birch tree at Nursery-1 and Nursery-2.

\begin{tabular}{lcccc}
\hline & \multicolumn{4}{c}{ Mean number of aphids } \\
\cline { 2 - 5 } & \multicolumn{2}{c}{ Nursery-1 } & \multicolumn{2}{c}{ Nursery-2 } \\
\cline { 2 - 5 } Yr & Conventional & Intelligent & Conventional & Intelligent \\
\hline 2017 & $81.0 \mathrm{a}^{\mathrm{z}}$ & $31.0 \mathrm{~b}$ & $34.0 \mathrm{~b}$ & $74.7 \mathrm{a}$ \\
2018 & $36.5 \mathrm{a}$ & $11.5 \mathrm{~b}$ & $17.9 \mathrm{a}$ & $15.4 \mathrm{~b}$ \\
2019 & $0.2 \mathrm{a}$ & $0.1 \mathrm{a}$ & $6.3 \mathrm{a}$ & $5.5 \mathrm{~b}$ \\
\hline
\end{tabular}

${ }^{\mathrm{z}}$ Means followed by different letters in the same year and same site are significantly different $(P \leq 0.05$ level) using a paired $t$ test.

Fruit Farm, the same plants and same plots were used for the three consecutive growing seasons from 2017 to 2019. Although the peach trees and black raspberry were trimmed to about the same sizes every year, the canopies of the apple trees and blueberry plants gradually increased. At Nursery-2, experiments were conducted in the same apple, maple, and dogwood trees and in the same plots during the three consecutive growing seasons. With the growth of plants, the canopies of plants gradually increased. These results indicated that use of intelligent spray application was of even greater benefit on young trees with multiyear crop cycles, due to the relatively wide spacing between trees. At Nursery-1, test plants were grown in a "pot in pot" multiple-row production system. Test plants and plots were changed every year due to harvest. Removal of trees for sale changed canopy structure and spacing of trees within plots. Thus, pesticide use did not increase in intelligent spray technology plots from 2017 to 2019.

Effects of conventional and intelligent spray applications on populations of insect pests. There was no significant difference ( $P \geq$ 0.05 ) between conventional and intelligent spray applications in the populations of codling moth in apple plots on any date from 2017 to 2019 at Fruit Farm (Fig. 2). In 2017 and 2019, the peaks of the first and second generations of codling moth occurred in late May and early August, respectively. In 2018, only a first generation of codling moth appeared. In 2017 and 2018, codling moth mating disruption dispensers were placed in the apple trees, in combination with pesticide applications, to control the codling moth. During the growing season of 2019 , no codling moth mating disruption dispensers were placed in the plots, and insecticides alone were used to control codling moth. Moreover, codling moth populations were much lower in 2019 than 2017 and 2018. Apple fruit damage by codling moth was also determined in the apples from three apple trees in each spray plot in 2019. Only one apple from conventional spray trees and one apple from intelligent spray trees were found to 

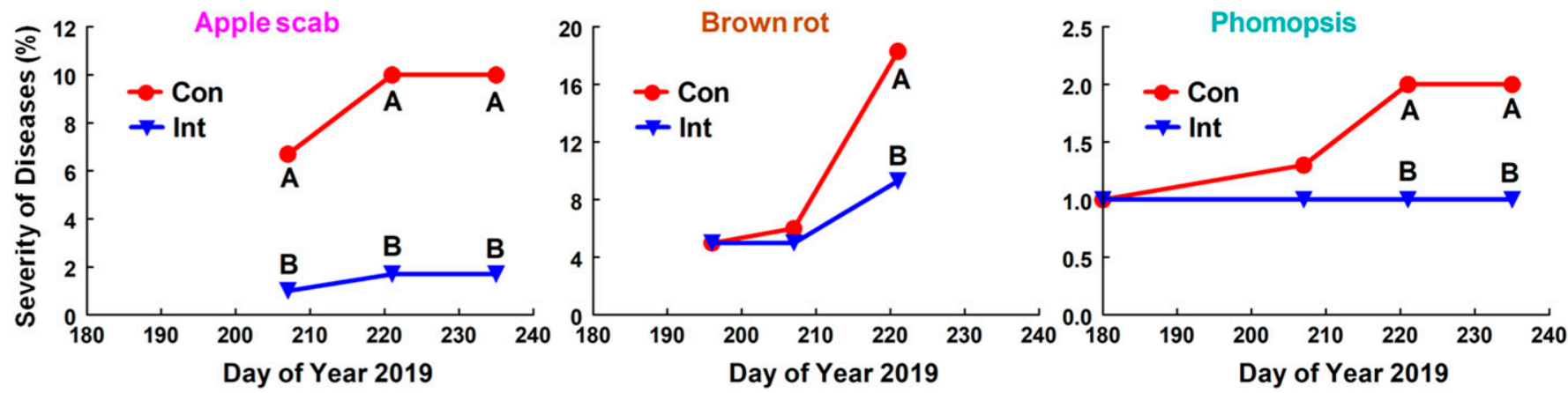

Fig. 3. Severity of diseases (\%) of scab in apple trees, brown rot in peach fruits, and phomopsis in blueberry plants treated with conventional constant-rate (Con) and intelligent variable-rate (Int) applications in 2019. Different letters in the same date are significantly different at the $P \leq 0.05$ level using a paired $t$ test.

be damaged by codling moth, and there was no difference between conventional and intelligent spray applications. These results demonstrate that intelligent spray technology was as effective controlling codling moths as conventional spray technology.

In 2017 and 2018, oriental fruit moth mating disruption dispensers and insecticides were applied to control oriental fruit moth in peach trees, and no oriental fruit moths were found during those seasons. In 2019, insecticides alone were used to control oriental fruit moth. No oriental fruit moths were found in traps in the conventional or intelligent spray treatments during 2019. The farm owner reported that oriental fruit moth was a traditional pest at the site. Pesticide applications are a primary tactic for controlling this pest. Our results indicate intelligent spray technology can control oriental fruit moth as effectively as conventional spray technology.

In blueberry plots, the analyses indicated no significant difference $(P \geq 0.05)$ in the number of SWD between conventional and intelligent spray treatments during 2017 and 2019 (Table 3). In 2018, no determination of SWD was conducted. SWD larvae in blueberry fruit were determined only in 2019, and only one larva was found in 450 blueberry fruits from the conventional test area, with no statistical difference between conventional and intelligent spray treatments. This result indicated that almost no blueberry fruits were damaged by SWD in conventional and intelligent spray plots. Blueberry fruit is susceptible to SWD, with yield of blueberry reduced by $30 \%$ to $100 \%$ in untreated plots (Fulcher et al., 2015). Few SWD were found in 2019 in the black raspberry plots. There was no difference $(P \geq 0.05)$ in the population of spotted wing drosophila between conventional and intelligent spray treatments. Thus, both intelligent and conventional spray treatments effectively controlled SWD in blueberry and black raspberry plots.

At Nursery-1, there was a decrease $(P \leq$ 0.05 ) in the number of leafhoppers in sticky traps in maple plots treated with intelligent spray technology in the 2018 growing season, compared with conventional spray technology (Table 4$)$. There was no difference $(P \geq$ $0.05)$ in the populations of leafhoppers between conventional and intelligent spray treatments in 2017 and 2019. At Nursery-2, intelligent spray treatments decreased the number of leafhoppers in maple plots in 2017 and 2018, but there was no difference in the population of leafhopper between the conventional and intelligent spray treatments in 2019. The decrease in leafhoppers with the intelligent spray treatment compared with the conventional spray treatment might have resulted from a reduction of adverse impacts to natural enemies of leafhoppers, because insecticides used for the test were broadspectrum insecticides not specific to leafhoppers, and because intelligent spray treatment reduced the spray drift to nontarget areas (Salcedo et al., 2020; Zhu et al., 2006b). These results demonstrated that intelligent spray application was more effective than conventional spray application to control leafhopper in maple trees.

At Nursery-1, the intelligent spray applications decreased $(P \leq 0.05)$ populations of aphids in birch trees in 2017 and 2018, compared with conventional spray applications (Table 5). Almost no aphids occurred in either treatment during the 2019 growing season, and no difference was found. At Nursery-2, intelligent spray applications decreased $(P \leq 0.05)$ populations of aphids in 2018 and 2019; while in 2017, the population of aphids increased, compared with conventional spray applications. For the same reason as the leafhoppers, the decrease of aphids for intelligent spray could have been a reduction of the spray drift to nontarget areas, reducing the adverse impact to the ecosystems, leading to an increase in the number of natural enemies of aphids. However, it is not clear why aphid populations were higher in the intelligent spray treatment in 2017. Probably because it was the first year to use the intelligent spray treatment, and the aphid population was already high in the area. Further investigations should be conducted for determining the reason. Nevertheless, these results demonstrated that use of intelligent spray treatments were usually more effective at controlling aphids in birch than conventional treatments.

Effects of conventional and intelligent spray applications on severity of diseases. At Fruit Farm, intelligent spray application decreased scab in apple trees, brown rot in

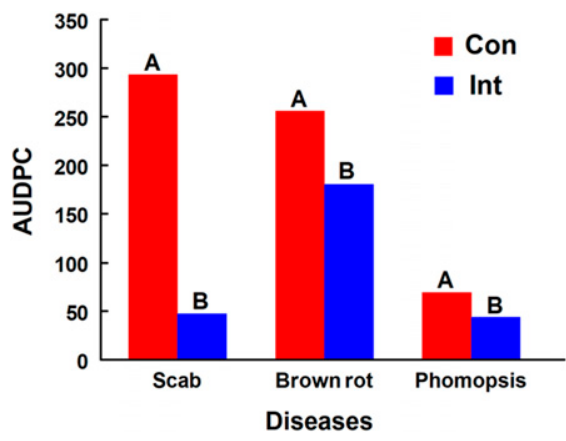

Fig. 4. Area under the disease progress curve (AUDPC) of scab in apple trees, brown rot in peach, and phomopsis in blueberry plants treated with conventional constant-rate (Con) and intelligent variable-rate (Int) applications at Fruit Farm in 2019. AUDPCs with different letters above the bars for the same disease are significantly different at the $P \leq 0.05$ level using a paired $t$ test.

peach fruits, and phomopsis in blueberry plants in 2019 (Figs. 3 and 4). No scab in apple trees or brown rot in peach fruits were found in either the conventional or intelligent treatments in 2017 and 2018. No phomopsis in blueberry plants was found in 2017. There was a decrease $(P \leq 0.05)$ of phomopsis in the intelligent spray treatment in 2018; AUDPC was 120 for conventional and 0 for intelligent spray. No powdery mildew in apple or peach trees and no mummy berry in blueberry occurred in either the conventional or intelligent treatment during 2017 to 2019. Sufficient pesticide coverage provided by the intelligent spray applications could explain the lack of difference in disease severities, compared with conventional spray. For the reduction of diseases by intelligent spray, it is possible that the reduced fungicide to the field in the intelligent spray treatment allowed nonpathogenic fungi to thrive and compete with pathogenic fungi (Salcedo et al., 2020; Zhu et al., 2006b).

For black raspberry, no anthracnose was detected in either treatment during 2017 and 2019. In 2018, anthracnose was less severe on black raspberry in the intelligent spray treatment than conventional; AUDPC was 1068 for conventional spray and 670 for intelligent spray. 
Table 6. Effects of conventional and intelligent spray treatments on the area under the disease progress curve (AUDPC) of scab in crabapple trees at Nursery-1 and in apple trees at Nursery-2.

\begin{tabular}{|c|c|c|c|c|}
\hline \multirow[b]{3}{*}{$\mathrm{Yr}$} & \multicolumn{4}{|c|}{ AUDPC } \\
\hline & \multicolumn{2}{|c|}{ Nursery-1 } & \multicolumn{2}{|c|}{ Nursery-2 } \\
\hline & Conventional & Intelligent & Conventional & Intelligen \\
\hline 2017 & $0^{z}$ & 0 & $631 \mathrm{~b}^{\mathrm{y}}$ & $821 \mathrm{a}$ \\
\hline 2018 & 0 & 0 & $4008 \mathrm{a}$ & $3435 \mathrm{~b}$ \\
\hline 2019 & 0 & 0 & $248 \mathrm{a}$ & $241 \mathrm{a}$ \\
\hline
\end{tabular}

${ }^{\mathrm{z}}$ No scab in crabapple trees was found in either the conventional or intelligent spray treatments during the three growing seasons at Nursery-1.

${ }^{\mathrm{y}}$ Means followed by different letters in the same year and same nursery site are significantly different $(P \leq$ 0.05 level) using a paired $t$ test.

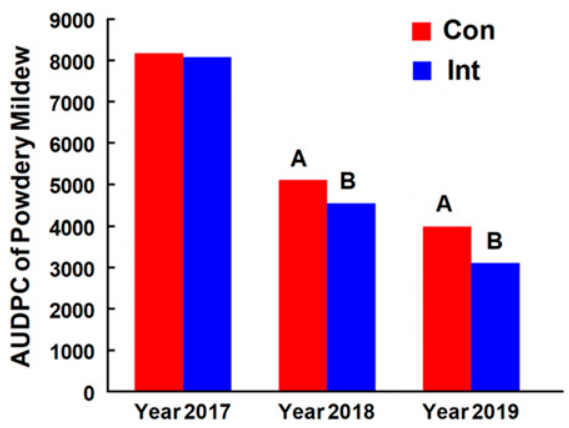

Fig. 5. Area under the disease progress curve (AUDPC) of powdery mildew in dogwood treated with conventional constant-rate (Con) and intelligent variable-rate (Int) applications at Nursery-2 from 2017 to 2019. AUDPCs with different letters above the bars are significantly different at the $P \leq 0.05$ level using a paired $t$ test.

At Nursery-1, no scab in crabapple trees was found in either the conventional or intelligent spray treatments during the three growing seasons (Table 6). Of note, there were many crabapple trees in the area close to the experiment site. Those trees were not sprayed, and apple scab occurred in almost all trees (personal observations). In our spray experiment, because the crabapple trees were sprayed 12 to 16 times during each growing season (Table 1), it was reasonable that no apple scab was detected for either conventional or intelligent spray treatments.

At Nursery-2, apple scab occurred every year because pesticides were applied only three to four times during one growing season (Table 1). There was no difference $(P \geq 0.05)$ in severity between intelligent and conventional spray applications in 2019 (Table 6). However, intelligent spray application decreased $(P \leq 0.05)$ apple scab in 2018, whereas in 2017 there was an increase in apple scab in the intelligent spray treatment. It is not clear why apple scab was more prevalent for intelligent spray, compared with conventional spray, in 2017. A possible reason was that 2017 was the first year to use the intelligent spray treatment and not enough nonpathogenic fungi could thrive and compete with pathogenic fungi in the test plot. In general, for controlling apple scab, intelligent spray usually had equivalent effectiveness as conventional spray.

Powdery mildew in dogwood trees at Nursery-2 was reduced $(P \leq 0.05)$ by intelli- gent spray applications in 2018 and 2019, but there was no significant difference in 2017 between conventional and intelligent spray applications (Fig. 5). Powdery mildew in dogwood trees occurred from June to October every year. From 2017 to 2019, AUDPC of powdery mildew in dogwood trees decreased trees are more susceptible to powdery mildew (Li et al., 2009). Flowering dogwood has been threatened by powdery mildew since 1994 in the United States. To control powdery mildew, fungicides must be applied at 2-week intervals during the growing season ( $\mathrm{Li}$ et al., 2009). Thus, intelligent spray technology could provide a highly efficient and environmentally friendly method for flowering dogwood producers.

\section{Conclusions}

Laser-guided variable-rate intelligent sprayers were equal or more effective than conventional spray technology for control of insect and disease pests in fruit farms and ornamental tree nurseries, while reducing $30 \%$ to $65 \%$ pesticide and foliar fertilizer portion of the spray drift delivered to nontarget areas (for example, ground and air) that wastes pesticides and foliar fertilizers and contaminates the environment. Thus, intelligent spray technology provided a highly efficient, low-cost, and environmentally and worker-friendly pesticide and foliar fertilizer spray technology for the fruit production and ornamental nursery industry.

\section{Literature Cited}

Anco, D.J. and M.A. Ellis. 2011. Mummy berry of blueberry. 9 May 2019. <https://ohioline.osu.edu/ factsheet/plpath-fru-46>.

Beckerman, J. 2018. Midwest fruit pest management guide 2019-2020. 21 Dec. 2018. <https://ag. purdue.edu/hla/hort/documents/id-465.pdfs

Blake, J., N. Doubrava, R.W. Miller, Jr., G. Schnabel, and J. Williamson. 2016. Peach diseases. 9 May 2019. <https://hgic.clemson.edu/ factsheet/peach-diseases $>$.

Braman, S.K., M. Chappell, J.-H. Chong, A. Fulcher, N.W. Gauthier, W.E. Klingeman, G. Knox, A. LeBude, J. Neal, S.A. White, C. Adkins, J. Derr, S. Frank, F. Hale, F.P. Hand, C. Marble, J. Williams-Woodward, and A. Windham. 2015. Pest management strategic plan for container and field-produced nursery crops: Revision 2015. A.V. LeBude and A. gradually (Fig. 5) because young dogwood use. This technology avoided a significant
Fulcher (eds.). Southern Region IPM Center, Raleigh, NC.

Brunner, J.F. and R.E. Rice. 1993. Oriental fruit moth. Orchard pest management online. 6 May 2019 $<$ http://treefruit.wsu.edu/crop-protection/opm/ oriental-fruit-moth>.

Chen, Y., H. Zhu, H.E. Ozkan, R.C. Derksen, and C.R. Krause. 2013b. Spray drift and off-target loss reductions with a precision air-assisted sprayer. Trans. ASABE 56:1273-1281, doi: 10.13031/trans.56.10173.

Chen, Y., H. Zhu, and H.E. Ozkan. 2012. Development of a variable rate sprayer with laser scanning sensor to synchronize spray outputs to tree structures. Trans. ASABE 55:773-781, doi: 10.13031/2013.41509.

Chen, Y., H.E. Ozkan, H. Zhu, R.C. Derksen, and C.R. Krause. 2013a. Spray deposition inside tree canopies from a newly developed variable rate air-assisted sprayer. Trans. ASABE 56:1263-1272, doi: 10.13031/trans.56.9839.

Division of Forestry, Ohio Department of Natural Resources. 2018. River birch. 16 Sept. 2020. $<\mathrm{http}$ ///forestry.ohiodnr.gov/riverbirch $>$.

Ellis, M.A. 2008. Scab of apple. 9 May 2019. $<$ https:// ohioline.osu.edu/factsheet/plpath-fru-23>.

Ellis, M.A. 2016a. Apple powdery mildew. 9 May 2019. $<$ https://ohioline.osu.edu/factsheet/plpath-fru-21>

Ellis, M.A. 2016b. Anthracnose of raspberry and blackberry. 9 May 2019. <https://ohioline.osu.edu/factsheet/plpath-fru-27>.

Fernandez-Cornejo, J., R. Nehring, C. Osteen, S. Wechsler, A. Martin, and A. Vialou. 2014. Pesticide use in U.S. Agriculture: 21 selected crops, 1960-2008, EIB-124, U.S. Department of Agriculture, Economic Research Service, May 2014.

Fessler, L., A. Fulcher, D. Lockwood, W. Wright, and H. Zhu. 2020. Advancing sustainability in tree crop pest management: Improving spray application rate with a laser-guided variable-rate sprayer in 'golden delicious' apple trees. HortScience 55(9):15221530, doi: 10.21273/HORTSCI15056-20.

Frank, S.D., W.E. Klingeman, S.A. White, and A. Fulcher. 2013. Biology, injury, and management of maple tree pests in nurseries and urban landscapes. J. Integr. Pest Mgt. 4(1):1-14, doi: 10.1603/IPM12007.

Fulcher, A., N.W. Gauthier, W.E. Klingeman, F. Hale, and S.A. White. 2015. Blueberry culture and pest, disease, and abiotic disorder management during nursery production in the southeastern U.S.: A review. J. Environ. Hort. 33(1):3347, doi: 10.24266/0738-2898-33.1.33.

Hartman, J.R. 2007. Peach fruit diseases. 9 May 2019. <https://plantpathology.ca.uky.edu/files/ ppfs-fr-t-09_0.pdf>.

Jasinski, J. 2017. Salt water test for spotted wing drosophila (SWD) larvae. 16 Sept. 2020. $<\mathrm{https}: / / \mathrm{cpb}-$ us-w2.wpmucdn.com/u.osu.edu/dist/1/8311/ files/2017/04/SWD-salttesthandout-updatedpnd335.pdf $>$.

Jeon, H.Y. and H. Zhu. 2012. Development of variable-rate sprayer for nursery liner applications. Trans. ASABE 55(1):303-312, doi: 10.13031/2013.41240.

Li, Y., M.T. Mmbaga, A. Windham, M.T. Windham, and R.N. Trigiano. 2009. Powdery mildew of dogwoods: Current status and future prospects. Plant Dis. 93:1084-1092, doi: 10.1094/PDIS-93-11-1084.

Madden, L.V., G. Hughes, and F. van den Bosch. 2007. The study of plant disease epidemics. American Phytopathological Society, St. Paul, MN.

Manandhar, A., H. Zhu, E. Ozkan, and A. Shah 2020. Techno-economic impacts of using laserguided variable-rate spraying system to retrofit on conventional constant-rate sprayers for 
pesticide savings in apple orchards. Precis. Agr. 113:1-16, doi: 10.1007/s11119-02009712-8.

Salcedo, R., H. Zhu, Z. Zhang, Z. Wei, L. Chen, E. Ozkan, and D. Falchieri. 2020. Foliar deposition and coverage on young apple trees with PWM-controlled spray systems. Comput. Electron. Agr. 178:105794, doi: 10.1016/j.compag.2020.105794.

Shen, Y., H. Zhu, H. Liu, Y. Chen, and E. Ozkan. 2017. Development of a laser-guided embeddedcomputer-controlled air-assisted precision sprayer. Trans. ASABE 60:1827-1838, doi: 10.13031/ trans. 12455 .

Stover, E., J. Salvatore, and F. Wirth. 2003. Pesticide spray reduction from using a sensor actuated spray system in Indian River grapefruit. HortTechnology 13(1):178-181, doi: 10.21273/ HORTTECH.13.1.0178.

U.S. Department of Agriculture/National Agricultural Statistics Service. 2011. Agricultural chemical use: Nursery and floriculture crops 2009. 16
Sept. 2020. <https://www.nass.usda.gov/Surveys/ Guide_to_NASS_Surveys/Chemical_Use/NurseryFloricultureChemicalUseFactSheet.pdf $>$.

UMass Extension. 2018. Integrated pest management program. 3 Dec. 2019. <https:// ag.umass.edu/integrated-pest-management/ ipm-guidelines/apple>.

Witte, W., M.T. Windham, A.S. Windham, F.A Hale, D.C. Fare, and W.K. Clatterbuck. 2000. Dogwoods for American gardens. Univ. Tenn. Ext. PB 1670. https://extension.tennessee.edu/ publications/Documents/PB1670.pdf.

Zhu, H., H. Liu, Y. Shen, H. Liu, and R.H. Zondag. 2017. Spray deposition inside multiple-row nursery trees with a laser-guided sprayer. J. Environ. Hort. 35(1):13-23, doi: 10.24266/ 0738-2898-35.1.13.

Zhu, H., J. Atland, R.C. Derksen, and C.R. Krause. 2011a. Optimal spray application rates for ornamental nursery liner production. HortTechnology 21(3):367-375, doi: 10.21273/ HORTTECH.21.3.367.
Zhu, H., R.D. Brazee, R.C. Derksen, R.D. Fox, C.R Krause, H.E. Ozkan, and K. Losely. 2006a. A specially designed air-assisted sprayer to improve spray penetration and air jet velocity distribution inside dense nursery crops. Trans. ASABE 49:1285-1294, doi: 10.13031/2013.22037.

Zhu, H., R.C. Derksen, H. Guler, C.R. Krause, and H.E. Ozkan. 2006b. Foliar deposition and offtarget loss with different spray techniques in nursery applications. Trans. ASABE 49:325334, doi: 10.13031/2013.20400.

Zhu, H., R.H. Zondag, C.R. Krause, J. Merrick, and J. Daley. 2011b. Reduced use of pesticides for effective controls of arthropod pests and plant diseases. J. Environ. Hort. 29(3):143-151, doi: 10.24266/0738-2898-29.3.143.

Zhu, H., R.H. Zondag, R.C. Derksen, M. Reding, and C.R. Krause. 2008. Influence of spray volume on spray deposition and coverage within nursery trees. J. Environ. Hort. 26(1):51-57, doi: 10.24266/0738-2898-26.1.51. 